\title{
Evaluation of Rice Genotypes of Sikkim and Tripura for Resistance to Brown Planthopper, Nilaparvata lugens (Stal)
}

\author{
Bodhnapod Navin Gangaram ${ }^{\text {1* }}$, Basana Gowda ${ }^{2}$, S. S. Shaw ${ }^{2}$, \\ S. K. Behera ${ }^{2}$, G. Guru Pirasanna Pandi ${ }^{2}$, Prajna Pati ${ }^{2}$, Mayabini Jena ${ }^{2}$, \\ S. Raghu' ${ }^{2}$, G. Prashanthi ${ }^{2}$ and Naveen Patil $^{2}$ \\ ${ }^{1}$ Crop Protection Division, ICAR -National Rice Research Institute, \\ Cuttack - 753006 (Odisha), India \\ ${ }^{2}$ Division of Entomology, ICAR - Indira Gandhi Krishi Vishvavidhyalay, \\ Raipur-492012(Chhattisgarh), India \\ *Corresponding author
}

\section{A B S T R A C T}

Studies were undertaken to evaluate the rice genotypes of Sikkim and Tripura for their resistance against brown planthopper (BPH) under glasshouse conditions. Among 74 rice

\section{Keywords}

$\mathrm{BPH}$, resistant, Antixenosis, Antibiosis

\section{Article Info}

Accepted: 20 July 2019 Available Online: 10 August 2019 genotypes phenotyped, a genotype (AC-39843) was considered as resistant and two other genotype (AC-39842 and AC-39877) of Tripura were categorized as moderately resistant to BPH. To understand their mechanism of resistance, resistant genotypes were evaluated for different parameter of antixenosis and antibiosis. The antixenosis and antibiosis studies in terms of nymphal setting preference, per cent unhatchability of eggs, nymphal survival and development, honeydew excretion, probing mark test, plant dry weight loss and defence enzymes (Peroxidase, polyphenol oxidaseand catalase) indicated that these genotypes showed confirmation of resistance to BPH compared to susceptible check TN 1 . Among resistant genotypes, AC-39843 recorded lowest sugar content followed by AC39842 and AC-39877 compared to TN1. Total phenol content in AC-39843 was highest followed by AC-39877 and AC-39842. Resistant genotypes found in the study could be used as new resistant donors and utilized in resistance breeding programme against brown planthopper in rice.

\section{Introduction}

'Rice is life' describes the importance of rice in human diet. It is one of the world's most important food crops and is infested by about 800 species of insect pests in both field and storage (Barrion and Litsinger, 1994).Among the insect pests, brown plant hopper (BPH), Nilaparvata lugens (Stal.) (Homoptera:
Delphacidae) is one of the most economically important insect pest which cause severe damage, where both nymphs and adults suck the plant sap directly andindirectly transmit viruses such as ragged stunt and grassy stunt (Khushand Brar, 1991). At early infestation, round and yellow patches appear, which soon turn brownish due to the drying up of the plants which is called as 'hopper burn', and 
results in huge yield loss ranging from 10-75 percent. A large number of insecticides including chlorinated hydrocarbons, organophosphates, carbamates, and systemic pyrethroids have been used for management of $\mathrm{BPH}$. But in order to provide the long lasting strategy host-plant resistance is an important option. Development of resistance rice cultivars through host plant resistance is generally considered to be the most economic and effective way for controlling $\mathrm{BPH}$ population. A total of 35 major $\mathrm{BPH}-$ resistance genes have been identified from cultivated rice and wild Oryza species (Wang et al., 2018). Many rice varieties with resistance to plant hopper have been developed and released to the farmers for commercial cultivation, however the situation become alarming when the resistance of these new varieties diminished because of apparent selection of pest. In order to manage this pest, chemical method is mostly used with the associated problems like insect resistance to insecticide, resurgence, destruction of natural enemies etc. Hence, ensuring the genetic resistance of host plants is the most effective and environmentally-friendly approach for the BPH management. In the quest for identifying $\mathrm{BPH}$ resistant genes, Sikkim and Tripura rice genotypes were selected because, being land races they might be have the large pool of $\mathrm{BPH}$ resistant genes.

\section{Materials and Methods}

\section{Plant material and Insects}

A total of 74 (seventy four) rice genotypes of Sikkim and Tripura were collected from ICAR-NRRI Gene Bank along with TN1 as standard susceptible check, Ptb33 and Salkathi as resistant checks. The BPH insects were field collected and were maintained on Taichung Native 1 (TN1, a susceptible indica variety) under net house of crop protection division of ICAR-NRRI Cuttack.

\section{Phenotyping for $\mathrm{BPH}$ resistance}

Screening of 70 landraces of Sikkim and Tripura rice accessions against brown plant hopper (BPH) were done as per Qiu et al., (2010). A bulk seedling test was conducted to evaluate $\mathrm{BPH}$ resistance. The pre-germinated seeds were sown as per standard seed box screening techniques at National Rice Research Institute, Cuttack $\left(20^{\circ} 45^{\prime} \mathrm{N}\right.$ latitude, $85^{\circ} 93^{\prime} \mathrm{E}$ longitude and $36 \mathrm{~m}$ altitude). Well germinated seeds were shown at $5 \times 1 \mathrm{~cm}$ apart plastic tray in rows at equal distance with 20 25 seedlings of each genotype along with resistance checks, Ptb33 and salkathi and susceptible check TN1.The $2^{\text {nd }}$ instar $\mathrm{BPH}$ nymphs were released in the screening trays containing 10-12 days old seedling (third-leaf stage) with almost 10 nymphs per seedling. Phenotypic values for the individual plants were recorded on a scale on $0-9$ when all plants of susceptible control TN1 were died. This was done following the Standard Evaluation System (SES) for rice (IRRI, 2013).

\section{Antixenosis}

\section{Nymphal setting preference}

Method nymphal setting preference was followed as per the method described by Heinrichs et al., (1985). From the results of phenotyping, only resistant genotypes along with TN1 (susceptible check) and Ptb33 (resistance check) seeds were sown in 50 x 40 x $7 \mathrm{~cm}$ plastic tray. After 10-12 days, two to three seedlings were transplanted in single earthen pot containing puddled homogeneous soil in circular fashion and TN1 seedlings in the centre. Four replicates were maintained. After 7-9 days of transplanting, $2^{\text {nd }}$ instar $\mathrm{BPH}$ nymphs were released by gently tapping over seedlings in such a way that approximately 10 nymphs settled on each seedling and pot was covered with plastic Mylar cage. Number of 
nymphs settled on each seedling was observed and recorded at 1, 2, 6, 12, 24, 48 and $72 \mathrm{~h}$ after infestation. The seedlings were disturbed after each count for reorientation of nymphs on seedlings.

\section{Ovipositional response (Total fecundity)}

It was carried out as per method of Reddy et al., (2005). The well germinated seedlings of resistant rice genotypes as well as susceptible check TN1 and resistant check Ptb33 were transplanted in 500-600 ml plastic pots filled with puddled soil. For each genotype, four replications were maintained. After 30 days, the plants were washed and cleaned by removing dried and excess leaves for convenient oviposition. Plants were well covered with mylarcages with ventilating windows. Three gravid female (seven days old) was released with the help of an aspirator into the cage and the open end of the tube was covered with a muslin cloth and tied with a rubber band.

The females were removed five days after release. The plants were observed for nymphal hatching. The number of hatched nymphs were recorded and removed from the plant. After all the eggs were hatched or when nymphs stop coming out (after 15-20 days of adult release) the plants were cut at the base and examined under stereo zoom microscope (Nikon SMZ 745T), total number of egg masses and number of unhatched eggs were recorded.

Unhatched eggs were expressed as percentage of total, which is sum of number of nymphs counted and the number of unhatched egg.

Total fecundity $=$ Number of emerged nymphs + Number of unhatched eggs

Number of unhatched eggs was expressed as percentage of total, which is sum of the number of nymphs emerged and number of unhatched eggs. This was given as follows,

Number of unhatched eggs

Per cent unhatched eggs $=$ $\mathrm{X} 100$

Number of nymphs Emerged + Number of unhatched eggs

\section{Antibiosis (Biochemical)}

\section{Honey dew excretion method}

Adult feeding as indicated by quantity of honeydew excreted was measured using the method developed by Pathak (1970). The seeds were sown in $500 \mathrm{ml}$ plastic pots filled with homogenized puddled soil. Two seedlings were planted in each pot and retained only one healthy seedling after 5-6 days. For each genotype, four replications were maintained.

A small hole was made in the middle of Whatman number 1 filter paper $(9 \mathrm{~cm}$ diameter) and a longitudinal incision was made from the margin towards centre of the hole. Bromocresol green solution $(0.02 \%)$ in ethanol was taken in a petridish and the filter paper were dipped in it and then shade dried. Card board sheets were taken and cut into square shapes of $12 \mathrm{X} 12 \mathrm{~cm}$ and a hole was made in the middle of the square. One month old seedlings were inserted through the hole and the card board squares were kept at the base of the plant and the hole was plugged with non-absorbent cotton. The treated filter paper circles were placed on the card board at the base of the plant. Small plastic cup without lid was taken and a small hole was at the base of the cup and the plants were inserted through the hole and the inverted cups were placed on the filter paper.

The honey dew excretion method of adults for feeding was carried out by five fresh female hoppers pre-starved for $4 \mathrm{~h}$ were released into 
chamber to feed on each test culture along with the resistant (Ptb 33) and susceptible (TN1) check. Four replications were maintained. The BPH adults were allowed to feed for 24 hours at the base of the stem. When the honeydew excreted by BPH comes in contact with the filter paper treated with Bromocresol green solution, spots with blue tinged margin were formed. Then the filter papers were taken out and the area of the spots were measured by graph paper method. The area of all the honeydew spots were traced on a millimetre square graph paper and the number of squares within the spots were counted. The area of all the honey dew spots was added and honeydew excretion was expressed as $\mathrm{mm}^{2}$ per 5 females.

\section{Probing mark test}

It was carried out as per the method suggested by Natio (1964). For this purpose, seeds of identified resistant rice genotypes and checks (TN1 and Ptb33) were germinated separately in petridishes. Germinated seeds were sown in plastic trays containing well puddled soil. After 30 days, the seeding of each genotype was washed thoroughly with water and then transferred individually into $15 \mathrm{~cm}$ long test tubes containing a few drops of water. Three emerged female were introduced individually into each test tube and test tubes were plugged with sterilized cotton swab. The female was allowed to make feed on the seedling for one day (24 hrs). Thereafter, the seedlings were taken for staining in another tube containing 1.0 per cent erythrosine dye aqueous solution. Insect probing marks stained thereby counted visually after 30 minutes of staining.

\section{Nymphal survival and development period}

Method of Heinrichs et al., (1985) was followed. Two seedlings per pot were transplanted in well puddled soil in a pot and four replications were maintained for each genotype. After 30 days, the resistant genotype along with checks were enclosed with glass chimney for each treatment $(8 \mathrm{~cm}$ Dia). Thirty, $1^{\text {st }}$ instar nymphs of BPH were released in each genotype.

The plants were observed daily and the number of nymphs that reached adulthood are counted and removed. The percent nymphal survival was calculated by

Number of emerged adults $\%$ Nymphal survival = ------------------ X 100

Number of released nymphs

Number of days required by nymph to turn into next instars was also recorded. On the basis of nymphal survival and development period, growth index (GI) of BPH on each genotype was calculated as follows

$\%$ nymphs survived on test culture Growth Index $(\mathrm{GI})=$

Development period of nymphs on test culture

\section{Functional plant loss index (FPLI)}

The well germinated seedlings of selected rice genotypes as well as checks, (TN1 and Ptb33) were transplanted in $500 \mathrm{ml}$ plastic pots filled with well puddled soil. Four replications were maintained of each genotype. To study the level of tolerance on 30-day-old seedlings, 50 $1^{\text {st }}$ instar nymphs were introduced onto each genotype and covered with glass chimney. Resistant as well as check genotypes were maintained without releasing $\mathrm{BPH}$ nymphs were served as control.

When the plant started to wilt, the brown plant hoppers were collected from each genotype individually in the test tube. The collected $\mathrm{BPH}$ insects were dried for $48 \mathrm{~h}$ in oven and weighed. Simultaneously the infested and uninfested plants were removed from pots along with their root system and washed 
thoroughly. Washed plants were air-dried for $3 \mathrm{~h}$ under room temperature, then oven dried at $70^{\circ} \mathrm{C}$ for $60 \mathrm{~h}$ and weighed the functional plant loss index (FPLI) and plant dry weight loss per mg of insect dry weight were calculated for all rice genotypes using the formulas of Panda and Heinrichs (1983) as indicated follows,

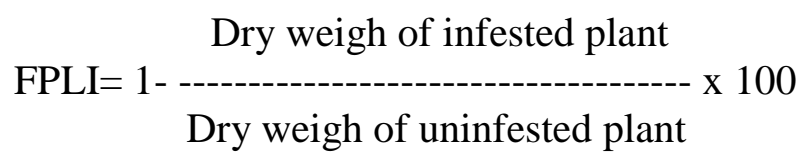

Plant dry weight loss per mg of $N$. lugens dry weight produced $=($ Dry weigh of uninfested plant - Dry weigh of infested plant / Dry weigh loss per mg of $N$. lugens progeny on infested plant)

\section{Results and Discussion}

\section{Phenotyping}

Of the phenotyped genotypes of Sikkim and Tripura, into 5 major categories based on their reaction against $\mathrm{BPH}$ as shown in below table 3.(Only one genotype of Tripura collection (AC-39843) was with SES score of 3 and damage percentage of $25 \%$; it was classified as Resistant (R); whereas, other two genotype of Tripura (AC-39842 and AC-39877) were with plant damage score of 5 and damage percentage of $47.82 \%$ and $41.17 \%$, respectively; classified under moderately resistant category (MR). The TN1 (Susceptible check) exhibited plant damage score of 9 with damage percentage was $100 \%$ and it was categorized as highly susceptible; whereas, standard resistant checkPtb33 with score 1 and damage percentage 12\% categorized as highly resistant to brown plant hopper

In recent years, $\mathrm{BPH}$ infestation on rice is on increasing trend. Host plant resistance is a major economic and desirable practice for the management of BPH (Chelliah, 1985). Resistant rice varieties can play a complementary role in minimizing insecticide use and to promote biological control in tropical rice (Way and Heong, 1994). In many instances, resistant cultivars synergize the effect of biological control agents that suppress pest population.

The release of resistant varieties by the International Rice Research Institute Las Bonos, Phillipines beginning with IR 26 in 1973 provided good control of BPH. Since then large number of resistant sources have been identified for planthoppers.

Systematic evaluation of the world collection of Oryzasativa began in 1967 and by 1986, 400 accessions out of 50,000 accessions screened and identified having resistance to $N$. Lugens (Rapusas and Heinrichs, 1987).

Our results did not corroborate the findings of Gajbhiye et al., (2017) who reported that a total of 22 rice accessions of $O$. latifolia were categorized as highly resistant, 7 accessions O.officinalis were categorized as moderately resistant, 6 accessions were categorized as susceptible and remaining 14 accessions and TN1were categorized as highly susceptible. Reason could be due to in the present findings we used O.sativa compared to wild species like O. latifolia and O.officinalis. Other studies which support present findings are of SiddeG owda (2009) and Sidde Gowda and Gubbaiah (2009) who screened 14,190 accessions of rice under Planthopper screening (PHS), National screening nursery (NSN) and Germplasm evaluation against major pests (GEMP) and identified 386 donors processing varied degree of resistance to $\mathrm{BPH}$. Rice cultivars IET 7575, IET 8116, IET 8110, IET 9912, IET 9873 and BPT 2217 were identified as brown planthopper resistant cultivars (Gubbaiah and Revanna, 1992; Shivamurthappa, 1993). 


\section{Antixenosis}

The major mechanisms involved in host plant resistance are antixenosis, antibiosis and tolerance (Painter, 1951). The utilization of plant's own defense mechanisms is an attractive area of researchall over the world to manage crop pests. The mechanisms of resistance need to be studied for ascertaining the degree of resistance among plants and it is essential for the development of durable resistant varieties. These resistant factors are heritable and they operate in a concerted manner to render plants unsuitable for insect pests. The concept of resistance mechanisms could be useful to entomologists and breeders as they work together to develop varieties with most effective type of resistance against pest population (Heinrichs et al., 1985).In the present study, Sikkim and Tripura rice genotypes which were resistant to BPH in glasshouse were further subjected to determine the mechanisms of resistance and the results of these studies are discussed hereunder.

\section{Nymphal settling preference:}

The resistant rice genotypes were screened for nymphal settling preference to know the antixenosis basis of resistance mechanism of rice genotypes. Out of 74 rice genotypes of Sikkim and Tripura, 3 resistant genotypes including standard checks TN1 and Ptb 33 were selected to study the nymphal setting preference of brown planthopper. The average nymphal settling preference score of rice genotypes were recorded and shown in Table 4.

There was significant among rice genotypes tested at all the time hours tested $(\mathrm{P}<0.0001)$. The average nymphs settled on resistant genotypes, AC-39843 (4.38), AC-39842 (6.19) and AC-39877 (6.24) was on par with Ptb33 (6.19) and were significantly different from susceptible check TN1 which recorded highest average nymphal settling (15.57). Similar trend of lower number of nymphal settling was also recorded on resistant genotypes at different time interval (Table 4).

Similar to findings of the present study, Soundrararajan et al., (2002) studied nymphal setting preference on doubled haploid lines at $12,24,48$ and $72 \mathrm{~h}$ after release and it was 2.18, 2.72, 3.61 and 4.36 nymphs per seedling, respectively. The highest population was observed in the susceptible check TN1 (4.34 nymphs) and the lowest was on resistant check Ptb 33 (1.88 nymphs).Likewise, studies of Bhanu et al., (2014) shown that highly resistant rice culture, MTU IJ 206-7-4-1 recorded least number of nymphs (3.22) while TN1 recorded the highest (12.01) and studies of Reddy et al., (2016) also found that resistant entries, IET-23620 and IET-23665 exhibited least number of BPH nymphs settled per plant (1.3 nymphs/ plant) compared to TN1 which recorded the highest number of nymphs (25.7 nymphs/ plant), thus both the studies corroborating the current findings.

\section{Ovipositional response (Total fecundity)}

Oviposition on plants by an insect greatly depends on the host plant preference. The present study revealed less number of eggs laid on the resistant genotypes as compared to susceptible check TN1. There was significant difference among the tested genotypes. With respect to fecundity of $\mathrm{BPH}$ on test genotypes, least number of eggs were laid on resistant check Ptb 33 (39) followed by AC-39877 (110.33) and AC-39843 (156.33). But eggs laid in another resistant genotype AC-39842 (199.67) was on par with the susceptible check, TN1 (178.67). But, least number of nymphs emerged from Ptb 33 (32) which was on par with AC-39842 (57.67), AC-39843 (38.67) and AC-39877 (43.67). TN1 had highest number of emerged nymphs (121). 
Over all, least number of eggs was laid and least number of nymphs was hatched in the resistant genotypes as compared to susceptible check TN1, thus indicating their nonpreference for egg laying (Table 5).

The mean number of nymph emerged was significantly high in susceptible check TN1 (121.00), than in all the tested genotypes and Ptb33. Among resistant genotypes, the nymphal emergence value was ranged from 32.00 to 57.67. The resistant check Ptb33 had the nymphal emergence value of 32.00 . The lowest number of nymph emergence was found in resistant rice genotypes like AC39843 (38.67) followed by AC-39877 (43.67) and AC-39842 (57.67), and it was little higher than Ptb33 (32.00) but lower than susceptible check TN1 (124.00).

The percent unhatched egg in resistant and moderately resistant genotypes was ranged from 57.75 to 76.32 per cent, whereas it was 16.67 per cent and 32.75 per cent in resistant check Ptb33 and susceptible check TN1, respectively. The highest percentage of unhatched eggs was found in the genotype AC-39843 (76.32 \%) followed by AC-39842 (71.56 \%) and AC-39877 (57.75\%).

The increasing percentage of unhatched (unfertile) eggs in resistance genotypes means, biochemical factors of resistant plants might be increased which exerted adverse effect on fertility of BPH eggs.

Similar observations were also made by Senguttuvan et al., (1991) and Alagar et al., (2007), where in, they reported less number of eggs and higher percent of unhatched eggs on Ptb 33 compared to susceptible check TN1. Wu et al., (1986) observed that, the resistant accessions were non-preferred and $N$. Lugenscaged on resistant accessions had low food, fecundity and consequently low populations. Oviposition of BPH was significantly high on susceptible check genotype TN1 and low on resistant genotypes. All the resistant genotypes exerted adverse effect on the oviposition of BPH.

\section{Antibiosis (Biochemical)}

\section{Honey dew excretion method}

Screened resistant and moderately resistant rice genotypes along with standard checks TN1 and Ptb 33 were selected to study brown planthopper honey dew excretion response and the amount of phloem in the honey dew excreted by the insect in the genotype was measured in $\mathrm{mm}^{2}$ units. There was a significant difference among the plant differentials. All the selected resistant genotypes exhibited average honeydew excretion values which varied from 219.67 to $284.67 \mathrm{~mm}^{2}$ per three female in $24 \mathrm{~h}$ (Table 6), which was significantly lower than the susceptible check TN1.

The highest feeding rate was observed in susceptible check TN1 (776.67 $\mathrm{mm}^{2} /$ three female). The resistance genotypes AC-39843 (219.67) had least honey dew area among the resistant genotypes followed by AC-39877 (331.33) and AC-39842 (284.67) but not with Ptb 33 resistant check. Resistant check Ptb33 had lowest honeydew excretion of $76.00 \mathrm{~mm}^{2}$ which was lower than other resistant rice genotypes tested.

Measuring honeydew excretion is a tool for assessing antibiosison feeding activity of sucking insects on resistant and susceptible varieties (Auclair, 1958). In the present study, number of honey dew secreted area by BPH was more and less in Ptb 33 and other resistant genotypes tested. Similar results were obtained by Paguia et al., (1980) where they found more area of honeydew excretion on filter papers in susceptible variety (TN1) compared to resistant varieties (Mudgo and ASD 7). 
Table.1 Phenotyping of rice germplasm of Tripura against BPH

\begin{tabular}{|c|c|c|c|c|c|c|}
\hline Sr. No & Rice accession & TP & DP & DP\% & Scoring & Rating \\
\hline 1 & AC-39842 & 23 & 11 & 47.82 & 5 & MR \\
\hline 2 & AC-39843 & 20 & 5 & 25 & 3 & $\mathrm{R}$ \\
\hline 3 & AC-39844 & 20 & 16 & 80 & 9 & HS \\
\hline 4 & AC-39845 & 20 & 19 & 95 & 9 & HS \\
\hline 5 & AC-39846 & 27 & 21 & 77.77 & 9 & HS \\
\hline 6 & AC-39847 & 23 & 18 & 78.26 & 9 & HS \\
\hline 7 & AC-39849 & 24 & 24 & 100 & 9 & HS \\
\hline 8 & AC-39850 & 23 & 22 & 95.62 & 9 & HS \\
\hline 9 & AC-39851 & 21 & 21 & 100 & 9 & HS \\
\hline 10 & AC-39852 & 20 & 20 & 100 & 9 & HS \\
\hline 11 & AC- -39853 & 14 & 14 & 100 & 9 & HS \\
\hline 12 & AC-39854 & 24 & 24 & 100 & 9 & HS \\
\hline 13 & AC-39855 & 12 & 12 & 100 & 9 & HS \\
\hline 14 & AC-39856 & 10 & 9 & 90 & 9 & HS \\
\hline 15 & AC-39857 & 14 & 14 & 100 & 9 & HS \\
\hline 16 & AC-39858 & 18 & 17 & 94.44 & 9 & HS \\
\hline 17 & AC-39859 & 28 & 24 & 85.71 & 9 & HS \\
\hline 18 & AC-39860 & 30 & 26 & 86.66 & 9 & HS \\
\hline 19 & AC-39861 & 25 & 25 & 100 & 9 & HS \\
\hline 20 & AC-39862 & 24 & 24 & 100 & 9 & HS \\
\hline 21 & AC-39863 & 25 & 25 & 100 & 9 & HS \\
\hline 22 & AC-39864 & 24 & 24 & 100 & 9 & HS \\
\hline 23 & AC-39866 & 24 & 23 & 95.83 & 9 & HS \\
\hline 24 & AC-39867 & 24 & 23 & 95.83 & 9 & HS \\
\hline 25 & AC-39868 & 25 & 25 & 100 & 9 & HS \\
\hline 26 & AC-39869 & 20 & 20 & 100 & 9 & HS \\
\hline 27 & AC-39870 & 15 & 10 & 70 & 7 & MS \\
\hline 28 & AC-39871 & 24 & 21 & 87.5 & 9 & HS \\
\hline 29 & AC-39872 & 25 & 23 & 92 & 9 & HS \\
\hline 30 & AC-39874 & 25 & 24 & 96 & 9 & HS \\
\hline 31 & AC-39875 & 23 & 23 & 100 & 9 & HS \\
\hline 32 & AC-39876 & 20 & 18 & 90 & 9 & HS \\
\hline 33 & AC-39877 & 17 & 7 & 41.17 & 5 & MR \\
\hline 34 & AC-39878 & 19 & 19 & 100 & 9 & HS \\
\hline 35 & AC-39879 & 19 & 17 & 89.84 & 9 & HS \\
\hline 36 & AC-39880 & 20 & 14 & 70 & 7 & MS \\
\hline 37 & AC-39881 & 15 & 10 & 70 & 9 & HS \\
\hline 38 & AC-39882 & 10 & 10 & 100 & 9 & HS \\
\hline 39 & AC-39883 & 28 & 28 & 100 & 9 & HS \\
\hline 40 & AC-39885 & 23 & 15 & 65.21 & 7 & MS \\
\hline 41 & AC-39886 & 15 & 10 & 75 & 9 & HS \\
\hline 42 & AC-39887 & 22 & 22 & 100 & 9 & HS \\
\hline 43 & AC-39888 & 23 & 23 & 100 & 9 & HS \\
\hline 44 & AC-39889 & 22 & 20 & 90.9 & 9 & HS \\
\hline 45 & AC-39891 & 23 & 23 & 100 & 9 & HS \\
\hline 46 & TN1 & 25 & 25 & 100 & 9 & HS \\
\hline 47 & Ptb 33 & 25 & 3 & 12 & 1 & HR \\
\hline
\end{tabular}


Table.2 Phenotyping of rice germplasm of Sikkim against BPH

\begin{tabular}{|c|c|c|c|c|c|c|}
\hline $\begin{array}{c}\text { Sr. } \\
\text { No }\end{array}$ & Rice accession & TP & DP & DP\% & Scoring & Rating \\
\hline $\mathbf{1}$ & AC-39737 & 23 & 17 & 73.91 & 9 & HS \\
\hline $\mathbf{2}$ & AC-39738 & 24 & 24 & 100 & 9 & HS \\
\hline $\mathbf{3}$ & AC-39739 & 12 & 12 & 100 & 9 & HS \\
\hline $\mathbf{4}$ & AC-39740 & 15 & 10 & 70 & 7 & MS \\
\hline $\mathbf{5}$ & AC-39741 & 10 & 10 & 100 & 9 & HS \\
\hline $\mathbf{6}$ & AC-39742 & 13 & 13 & 100 & 9 & HS \\
\hline $\mathbf{7}$ & AC-39744 & 11 & 11 & 100 & 9 & HS \\
\hline $\mathbf{8}$ & AC-39746 & 16 & 13 & 81.25 & 9 & HS \\
\hline $\mathbf{9}$ & AC-39747 & 20 & 20 & 100 & 9 & HS \\
\hline $\mathbf{1 0}$ & AC-39750 & 14 & 14 & 100 & 9 & HS \\
\hline $\mathbf{1 1}$ & AC-39751 & 16 & 11 & 68.75 & 7 & MS \\
\hline $\mathbf{1 2}$ & AC-39752 & 23 & 23 & 100 & 9 & HS \\
\hline $\mathbf{1 3}$ & AC-39753 & 28 & 18 & 64.28 & 7 & MS \\
\hline $\mathbf{1 4}$ & AC-39754 & 17 & 17 & 100 & 9 & HS \\
\hline $\mathbf{1 5}$ & AC-39756 & 21 & 15 & 71.42 & 9 & HS \\
\hline $\mathbf{1 6}$ & AC-39757 & 24 & 22 & 91.66 & 9 & HS \\
\hline $\mathbf{1 7}$ & AC-39759 & 15 & 15 & 100 & 9 & HS \\
\hline $\mathbf{1 8}$ & AC-39760 & 26 & 13 & 50 & 5 & MS \\
\hline $\mathbf{1 9}$ & AC-39761 & 25 & 24 & 96 & 9 & HS \\
\hline $\mathbf{2 0}$ & AC-39762 & 15 & 12 & 80 & 9 & HS \\
\hline $\mathbf{2 1}$ & AC-39769 & 22 & 21 & 95.45 & 9 & HS \\
\hline $\mathbf{2 2}$ & AC-39770 & 25 & 21 & 84 & 9 & HS \\
\hline $\mathbf{2 3}$ & AC-39772 & 21 & 15 & 71.42 & 9 & HS \\
\hline $\mathbf{2 4}$ & AC-39776 & 17 & 15 & 88.23 & 9 & HS \\
\hline $\mathbf{2 5}$ & AC-39777 & 14 & 13 & 92.85 & 9 & HS \\
\hline $\mathbf{2 6}$ & AC-39780 & 18 & 15 & 83.33 & 9 & HS \\
\hline $\mathbf{2 7}$ & AC-39781 & 24 & 24 & 100 & 9 & HS \\
\hline $\mathbf{2 8}$ & AC-39782 & 15 & 15 & 100 & 9 & HS \\
\hline $\mathbf{2 9}$ & AC-39784 & 24 & 23 & 95.83 & 9 & HS \\
\hline $\mathbf{3 0}$ & TN1 & 25 & 25 & 100 & 9 & HS \\
\hline $\mathbf{3 1}$ & Ptb 33 & 25 & 3 & 12 & 1 & HR \\
\hline $\mathbf{2 5}$ & & & & 9 & 9 \\
\hline
\end{tabular}

Note: TP: Total plant, DP: Dead plant, HS: Highly Susceptible, MS: Moderately Susceptible, MR: Moderately Resistant, HR: Highly Resistant, R: Resistant 
Table.3 Summary of BPH reaction of rice germplasm of Sikkim and Tripura

\begin{tabular}{|c|c|c|}
\hline $\begin{array}{c}\text { Average plant damage } \\
\text { score (Range) }\end{array}$ & $\begin{array}{c}\text { Rice germplasmof Sikkim and } \\
\text { Tripura }\end{array}$ & Rating \\
\hline $\mathbf{0 - 1}$ & 0 & Highly Resistant \\
\hline $\mathbf{1 - 3}$ & 1-Tripura & Resistant \\
\hline $\mathbf{3 - 5}$ & 2-Tripura & Moderately Resistant \\
\hline $\mathbf{5 - 7}$ & 1Tripura and 1 Sikkim & Moderately Susceptible \\
\hline $\mathbf{7 - 9}$ & 70 Sikkim and Tripura & Highly Susceptible \\
\hline
\end{tabular}

Table.4 Settling behavior of BPH nymphs on test genotypes at different time interval

\begin{tabular}{|c|c|c|c|c|c|c|c|c|}
\hline \multirow{2}{*}{$\begin{array}{c}\text { Rice } \\
\text { Genotypes }\end{array}$} & \multicolumn{7}{|c|}{ Number of nymphs settled } & \multirow{2}{*}{$\begin{array}{l}\text { Avg. No. } \\
\text { of nymphs } \\
\text { on test } \\
\text { genotypes }\end{array}$} \\
\hline & $1 \mathrm{hr}$ & $2 \mathrm{hr}$ & $6 \mathrm{hr}$ & $20 \mathrm{hr}$ & $24 \mathrm{hr}$ & $48 \mathrm{hr}$ & $72 \mathrm{hr}$ & \\
\hline AC-39842 & $6.00^{\mathrm{C}}$ & $7.67^{\mathrm{B}}$ & $6.00^{\mathrm{B}}$ & $7.00^{\mathrm{BC}}$ & $5.67^{\mathrm{B}}$ & $6.00^{\mathrm{B}}$ & $5.00^{\mathrm{B}}$ & $6.19^{\mathrm{AC}}$ \\
\hline AC-39843 & $3.67^{\mathrm{C}}$ & $5.00^{\mathrm{B}}$ & $5.67^{\mathrm{B}}$ & $5.67^{\mathrm{C}}$ & $2.67^{\mathrm{C}}$ & $5.00^{\mathrm{B}}$ & $3.00^{\mathrm{B}}$ & $4.38^{\mathrm{C}}$ \\
\hline TN1 & $18.00^{\mathrm{A}}$ & $18.00^{\mathrm{A}}$ & $15.67^{\mathrm{A}}$ & $13.67^{\mathrm{A}}$ & $15.00^{\mathrm{A}}$ & $14.67^{\mathrm{A}}$ & $14.00^{\mathrm{A}}$ & $6.24^{\mathrm{B}}$ \\
\hline AC-39877 & $12.00^{\mathrm{B}}$ & $5.67^{\mathrm{B}}$ & $3.67^{\mathrm{B}}$ & $9.67^{\mathrm{B}}$ & $4.00^{\mathrm{BC}}$ & $4.67^{\mathrm{B}}$ & $4.00^{\mathrm{B}}$ & $15.57^{\mathrm{A}}$ \\
\hline Ptb33 & $6.00^{\mathrm{C}}$ & $9.00^{\mathrm{B}}$ & $7.67^{\mathrm{B}}$ & $6.00^{C}$ & $4.67^{\mathrm{B}}$ & $7.00^{\mathrm{B}}$ & $3.00^{\mathrm{B}}$ & $6.19^{\mathrm{AC}}$ \\
\hline F value & 21.013 & 26.29 & 21.21 & 23.85 & 182.25 & 54.75 & 54.25 & 126.06 \\
\hline$P$ value & 0.0001 & $<.0001$ & 0.0001 & $<.0001$ & $<.0001$ & $<.0001$ & $<.0001$ & $<.0001$ \\
\hline
\end{tabular}

Table.5 Ovipositional response of three BPH on resistant genotypes

\begin{tabular}{|c|c|c|c|c|}
\hline $\begin{array}{c}\text { Sr. } \\
\text { no. }\end{array}$ & Rice genotypes & $\begin{array}{c}\text { Fecundity } \\
\text { (No.) }\end{array}$ & $\begin{array}{c}\text { No. ofnymph } \\
\text { emerged }\end{array}$ & $\begin{array}{c}\text { \% unhatched } \\
\text { eggs }\end{array}$ \\
\hline $\mathbf{1}$ & $\mathbf{A C - 3 9 8 4 2}$ & $199.67^{\mathrm{A}}$ & $57.67^{\mathrm{B}}$ & $71.56^{\mathrm{A}}$ \\
\hline $\mathbf{2}$ & $\mathbf{A C - 3 9 8 4 3}$ & $156.33^{\mathrm{AB}}$ & $38.67^{\mathrm{B}}$ & $76.32^{\mathrm{A}}$ \\
\hline $\mathbf{3}$ & $\mathbf{A C - 3 9 8 7 7}$ & $110.33^{\mathrm{B}}$ & $43.67^{\mathrm{B}}$ & $57.75^{\mathrm{AB}}$ \\
\hline $\mathbf{4}$ & $\mathbf{T N 1}$ & $178.67^{\mathrm{A}}$ & $121.00^{\mathrm{A}}$ & $32.75^{\mathrm{BC}}$ \\
\hline $\mathbf{5}$ & Ptb 33 & $39.00^{\mathrm{C}}$ & $32.00^{\mathrm{B}}$ & $16.64^{\mathrm{C}}$ \\
\hline $\mathbf{6}$ & F value & 23.875 & 8.260 & 16.651 \\
\hline $\mathbf{7}$ & P value & $<.0001$ & 0.0033 & 0.0012 \\
\hline
\end{tabular}


Table.6 Honey dew experiment of BPH on different test genotypes

\begin{tabular}{|c|c|c|}
\hline Sr. No. & Treatment & Honey dew area $\left.\mathbf{( m m}^{\mathbf{2}}\right)$ \\
\hline $\mathbf{1}$ & $\mathbf{A C - 3 9 8 4 2}$ & $284.67^{\mathrm{BC}}$ \\
\hline $\mathbf{2}$ & $\mathbf{A C - 3 9 8 4 3}$ & $219.67^{\mathrm{BC}}$ \\
\hline $\mathbf{3}$ & $\mathbf{A C - 3 9 8 7 7}$ & $331.33^{\mathrm{B}}$ \\
\hline $\mathbf{4}$ & $\mathbf{T N 1}$ & $776.67^{\mathrm{A}}$ \\
\hline $\mathbf{5}$ & Ptb33 & $76.00^{\mathrm{C}}$ \\
\hline $\mathbf{6}$ & F value & 9.537 \\
\hline $\mathbf{7}$ & P value & $<.0001$ \\
\hline
\end{tabular}

Table.7 Probing mark test of three female BPH on different test genotypes

\begin{tabular}{|c|c|c|}
\hline Sr. No. & Resistance rice genotypes & Number of probing mark \\
\hline $\mathbf{1}$ & $\mathbf{A C - 3 9 8 4 2}$ & $51.67^{\mathrm{D}}$ \\
\hline $\mathbf{2}$ & $\mathbf{A C - 3 9 8 4 3}$ & $68.67^{\mathrm{C}}$ \\
\hline $\mathbf{3}$ & $\mathbf{A C - 3 9 8 7 7}$ & $52.67^{\mathrm{D}}$ \\
\hline $\mathbf{4}$ & $\mathbf{T N 1}$ & $31.00^{\mathrm{E}}$ \\
\hline $\mathbf{5}$ & Salkathi & $90.00^{\mathrm{B}}$ \\
\hline $\mathbf{6}$ & Ptb33 & $105.00^{\mathrm{A}}$ \\
\hline & F value & 122.55 \\
\hline & P value & $<.0001$ \\
\hline
\end{tabular}

Table.8 Nymphal survival and development period on test genotypes

\begin{tabular}{|c|c|c|c|c|c|c|c|c|}
\hline \multirow[t]{2}{*}{ Genotypes } & \multicolumn{8}{|c|}{$\begin{array}{l}\text { Nymphs tested for survival and development period on resistance and } \\
\text { susceptible genotypes }\end{array}$} \\
\hline & $\begin{array}{l}1^{\text {st }} \\
\text { instar }\end{array}$ & $\begin{array}{l}\text { Surviv } \\
\text { al } \%\end{array}$ & $\begin{array}{l}2^{\text {nd }} \\
\text { instar }\end{array}$ & $\begin{array}{l}\text { Survi } \\
\text { val \% }\end{array}$ & $\begin{array}{l}\text { 3rd } \\
\text { instar }\end{array}$ & $\begin{array}{l}\text { Surviv } \\
\text { al } \%\end{array}$ & $\begin{array}{l}\text { 4th } \\
\text { instar }\end{array}$ & $\begin{array}{l}\text { Survival } \\
\%\end{array}$ \\
\hline AC-39842 & $28.00^{\mathrm{B}}$ & $93.33^{\mathrm{B}}$ & $26.33^{A}$ & $87.78^{\mathrm{A}}$ & $22.33^{B}$ & $74.44^{\mathrm{B}}$ & $11.67^{\mathrm{B}}$ & $38.89^{\mathrm{B}}$ \\
\hline AC-39843 & $29.00^{\mathrm{AB}}$ & $96.67^{\mathrm{AB}}$ & $27.00^{\mathrm{A}}$ & $90.00^{\mathrm{A}}$ & $16.00^{C}$ & $53.33^{C}$ & $5.00^{\mathrm{C}}$ & $16.67^{C}$ \\
\hline AC-39877 & $29.67^{\mathrm{A}}$ & $98.89^{\mathrm{A}}$ & $27.33^{A}$ & $91.11^{\mathrm{A}}$ & $23.67^{\mathrm{B}}$ & $78.89^{\mathrm{B}}$ & $10.00^{B}$ & $33.33^{\mathrm{B}}$ \\
\hline TN1 & $29.00^{\mathrm{AB}}$ & $96.67^{\mathrm{AB}}$ & $27.67^{A}$ & $92.22^{\mathrm{A}}$ & $27.67^{A}$ & $92.22^{\mathrm{A}}$ & $24.00^{\mathrm{A}}$ & $80.00^{\mathrm{A}}$ \\
\hline Ptb33 & $20.00^{C}$ & $66.67^{\mathrm{C}}$ & $13.00^{\mathrm{B}}$ & $43.33^{\mathrm{B}}$ & $1.00^{\mathrm{D}}$ & $3.33^{\mathrm{D}}$ & $1.00^{\mathrm{D}}$ & $3.33^{\mathrm{D}}$ \\
\hline F value & 182.87 & $\begin{array}{l}182.87 \\
5\end{array}$ & 54.42 & 54.425 & 546.55 & 546.76 & 364.15 & 364.22 \\
\hline$P$ value & $<.0001$ & $<.0001$ & $<.0001$ & $\begin{array}{c}<.000 \\
1\end{array}$ & $<.0001$ & $<.0001$ & $<.0001$ & $<.0001$ \\
\hline
\end{tabular}


Table.9 Development period and growth index (GI) of BPH on test genotypes

\begin{tabular}{|c|c|c|c|}
\hline Sr. No. & Genotypes & Development Period & Growth Index (GI) \\
\hline 1 & AC-39842 & $16.33^{\mathrm{B}}$ & $2.38^{\mathrm{B}}$ \\
\hline 2 & AC-39843 & $18.33^{\mathrm{AB}}$ & $0.91^{\mathrm{C}}$ \\
\hline 3 & AC-39877 & $17.00^{\mathrm{B}}$ & $1.96^{\mathrm{B}}$ \\
\hline 4 & TN1 & $12.33^{\mathrm{C}}$ & $6.50^{\mathrm{A}}$ \\
\hline 5 & Ptb33 & $19.67^{\mathrm{A}}$ & $0.15^{\mathrm{D}}$ \\
\hline 6 & F value & 34.6000 & 270.767 \\
\hline 7 & $P$ value & $<.0001$ & $<.0001$ \\
\hline
\end{tabular}

Table.10 FPLI and PD of resistant rice genotypes against BPH

\begin{tabular}{|c|c|c|c|c|c|}
\hline Genotypes & $\begin{array}{c}\text { Dry weight of } \\
\text { BPH } \\
\text { Uninfested } \\
\text { Plant (gm) }\end{array}$ & $\begin{array}{c}\text { Dry Weight of } \\
\text { BPH Infested } \\
\text { Plant (gm) }\end{array}$ & FPLI (\%) & $\begin{array}{c}\text { Dry weight } \\
\text { of BPH on } \\
\text { infested } \\
\text { plant (gm) }\end{array}$ & PD (mg) \\
\hline AC-39842 & $0.35^{\mathrm{C}}$ & $0.29^{\mathrm{C}}$ & $18.82^{\mathrm{B}}$ & $0.01^{\mathrm{B}}$ & $9.29^{\mathrm{B}}$ \\
\hline AC-39843 & $0.51^{\mathrm{AB}}$ & $0.45^{\mathrm{A}}$ & $12.94^{\mathrm{B}}$ & $0.01^{\mathrm{A}}$ & $5.66^{\mathrm{B}}$ \\
\hline AC-39877 & $0.44^{\mathrm{BC}}$ & $0.36^{\mathrm{B}}$ & $18.82^{\mathrm{B}}$ & $0.01^{\mathrm{AB}}$ & $8.27^{\mathrm{B}}$ \\
\hline TN1 & $0.56^{\mathrm{A}}$ & $0.28^{\mathrm{C}}$ & $49.97^{\mathrm{A}}$ & $0.01^{\mathrm{AB}}$ & $31.05^{\mathrm{A}}$ \\
\hline Salkathi & $0.41^{\mathrm{C}}$ & $0.38^{\mathrm{B}}$ & $8.79^{\mathrm{B}}$ & $0.01^{\mathrm{B}}$ & $5.48^{\mathrm{B}}$ \\
\hline F value & 33.969 & 21.905 & 52.905 & 6.385 & 11.713 \\
\hline P value & 0.0004 & 0.0001 & $<.0001$ & 0.0081 & 0.0009 \\
\hline
\end{tabular}

FPLI - Functional Plant Loss Index (\%)

PD - Plant dry weight loss per mg of insect dry weight produced.

Also, Kim et al., (1998) reported less amount honeydew excretion on resistant cultivars. Likewise honeydew excretion was less in the high $\mathrm{Si}$ addition treatment $(50 \mathrm{mg})$ than in the control $(30 \mathrm{mg})$ as reported by Yang et al., (2017).

\section{Probing mark test}

The average probing behaviour of BPH on resistant rice genotypes along with standard checks TN1, Ptb33 and salkathi are presented in (Table 7). The average number of probing marks by three adult gravid female of brown planthopper varied from 31.00 to 105.00 .

There was significant difference among tested genotypes $(\mathrm{P}<0.0001)$. The resistant genotype
AC-39842 had the average probing marks of 51.67, which was on par with AC-39877 which had 52.67 marks. Whereas, AC-39843 had 68.67 marks which was significantly different from aforementioned genotypes. The average probing mark per seedling in resistant check Ptb 33 was 105, which was significantly higher than three resistant genotypes.Among all resistant genotype tested, the genotype AC-39842 had the lowest (51.67) average probing marks per seedling. Among the checks, the lowest probing marks (31.00) were observed in TN1.Similar work has been carried out by Alagar et al., (2008) who reported that, the maximum number of feeding marks were observed on resistant ARC 10550 (43.80), which was 4.52 times higher than TN1. 
Nymphal survival and development period

Brown planthopper nymphal survival and development period as an indicator of antibiosis was carried out on resistant genotypes along with standard checks. All the test genotypes exhibited significant difference among themselves $(\mathrm{P}<0.0001)$. In the $1^{\text {st }}$ instar, least nymphal survival percentage was observed in Ptb 33 (66.67) and highest was in AC-39877 (98.89). The survival percentage of $1^{\text {st }}$ instar to $4^{\text {th }}$ instar BPH on resistant genotypes was significantly lower than the susceptible check TN1 (96.67 to 80.00) (Table 8).

Whereas developmental period of test genotypes ranged from 12.33 to 19.67 days, and were significantly different $(P<.0001)$. In TN1, nymphal survival percentage was significantly higher and developmental period was significantly lower than in all the resistant genotypes including resistant check Ptb 33. Resistant check Ptb 33 showed nymphal survival of 3.33 per cent at $4^{\text {th }}$ instar, which was significantly lower than AC39842, AC-39843 and AC-39877 genotypes and susceptible check TN1. Whereas, the developmental period of BPH on Ptb 33 was highest (19.67), which was significantly higher than 3 resistant genotypes and also susceptible check TN1.

In all the resistant genotypes tested, the genotype AC-39843 had the lowest $3^{\text {rd }}$ and $4^{\text {th }}$ instar nymphal survival value (53.33 and $16.67 \%$ ) followed by genotype AC-39877 and AC-39842, but it was significantly lower than the susceptible check variety TN1.

Among all the resistant genotypes tested, the genotype AC-39843 had the lower developmental period (18.33 days) followed by AC-39877 (17.00 days) and AC-39842 (16.33 days), but it was significantly higher than the susceptible check TN1 (12.33).
Survival rate determines the effect of antibiosis factors on nymphal stage (Heinrichs et al., 1985). The per cent nymphal survival was found to be less on resistant genotype Ptb $33(3.33 \%)$. Recently similar work has been reported by Jena et al.,(2015), where nymphal survival in all highly resistant(score 1) farmers' varieties ranged within 10.8 to $29.2 \%$ and were significantly lower than susceptible check TN1. Results Alagar et al., (2007) also corroborates our finding wherein the resistant genotypes ADT 45, Ptb 33and ASD 7 had the lowest nymphal survival rate than the susceptible TN1. Similarly, Nanda et al., (1997) reported very low nymphal survival of BPH in resistant varieties. Dharma and Mishra (1995) reported that the survival of BPH nymphs was less on all varieties tested, than on the susceptible check (TN1). The nymphal survival ranged between 43.30 and 83.30 per cent for most of the cultivars, except TN1, where 96.70 per cent of the nymphs survived. With respect to nymphal development, our findings supports the study of Bhanu et al., (2014) who found that MTU IJ 206-7-4-1 recorded significantly prolonged development period of nymphs (26.00 days) than the susceptible check TN1 (8.48)

The growth index (GI) of BPH on different resistant genotypes was lower than susceptible check TN1. Among resistant genotypes, line AC-39843 had GI of 0.91 which was followed by AC-39877 (1.96) and AC-39842 (2.38). The lowest growth index was seen in resistant check Ptb $33(0.15)$ and highest growth index was recorded in TN1 (6.50) Table 9.

\section{Functional plant loss index (FPLI)}

The Functional Plant Loss Index (FPLI) due to BPH infestation was more in susceptible genotype than in resistant genotypes and there exists significant difference among themselves. Among the resistant genotypes, 
AC-39843 had lowest FPLI (12.94) followed by AC-39842 (18.82) and AC-39877 (18.82). All these genotypes were on par with each other and were significantly different from resistant and susceptible checks. The resistant check Salkathi recorded lower FPLI (8.79) (Table 10).

The plant dry weight loss per mg of insect dry weight produced was lower in Salkathi (5.48mg) followed by resistant genotypes AC-39843 (5.66 mg), AC-39877 (8.27 mg) and AC-39842 (9.29 mg) which were on par with each other. Susceptible TN1 had 31.05 mg which was significantly high as compared to other tested genotypes (Table 10).

All the resistant genotypes recorded lower FPLI compared to susceptible genotype, TN1. The present findings were in conformity with Alagar et al., (2007), who reported lowest FPLI in Ptb 33 compared to susceptible genotype TN1. Further it was observed that Oryza rufipogan and O. nivara had lower FPLI compared to O. perenis and IR $26(\mathrm{Wu}$ et al., 1986).

Our results found the resistant genotype for the management of BPH by suppressing the feeding behavior, growth and longevity of $\mathrm{BPH}$ insects. This can in turn facilitate the development of BPH-resistant rice varieties in the future and help limit pesticide use. Resistant genotypes found in the study could be used as new resistant donors and utilized in resistance breeding programme against brown planthopper in rice.

\section{References}

Alagar, M., Suresh S., Samiyappan, R. and Saravana, K. D. (2007) Reaction of resistant and susceptible rice genotypes against brown planthopper (Nilaparvata lugens) Phytoparasitica 35: 346-56.

Alagar, M., Suresh, S. and Saravanan, P. A.
(2008) Feeding behaviour of Nilaparvata lugenson selected rice genotypes. Ann. Pl. Protc. Sci. 16 (1): 43-45.

Auclair, J. L. (1958) Honeydew excretion in the pea aphid, Acyrthosiphonpisum (Harr.) (Homoptera: Aphididae). Journal of insect Physiology, 2(4), 330337.

Barrion and Litsinger (1994) Taxonomy of rice insect pests and their arthropod parasites and predators.

Bhanu, K. V., Lakshmi, V. J., Katti, G., and Reddy, A. V. (2014) Antibiosis and tolerance mechanisms of resistance in rice varieties carrying brown planthopper resistance genes. Asian J. Biol. Life Sci, 3(10).

Chelliah, S. (1985) Genetics of resistance in rice to plant and leafhoppers. In International Rice Genetics Symposium, Los Banos, Laguna (Philippines), 27-31 May 1985.

Dharma R, K. and Misra, D. S. (1995) Screening of rice varieties against green leaf hoppers Nephotettix virescens (Distant) and N.nigropictus(Stal).Indian J. Ent., 57 (3): 179-191.

Gajbhiye, R. K., A. Kumar, N. pandey and S. Sharma (2017) Anatomical Studies of Wild Rice Accession for Evaluation of Resistance against Brown Plant Hopper. Int.J.Curr.Microbiol.App.Sci(2017) 6(5): 2493-2500.

Gubbaiah and Revanna, H. P. (1992) Promising rice cultures resistant to rice brown planthopper.Curr. Res., 21: 160161.

Heinrichs, E. A. (1985) Genetic evaluation for insect resistance in rice. Int. Rice Res. Inst.

IIRI, (2013) Standard Evaluation System (SES) for Rice, International Rice Research Institute, P.O. Box 933, 1099 Manila, Philippines.

Jena, M., Panda, R. S., Sahu, R. K., 
Mukherjee, A. K., \&Dhua, U. (2015) Evaluation of rice genotypes for rice brown plant hopper resistance through phenotypic reaction and genotypic analysis. Crop Protection, 78, 119-126.

Khush and Brar (1991) Genetics of resistance to insects in crop plants. Advances in Agronomy 45: 223-274.

Kim, M., Cohen, M. B., Roh, J., Kim, Y. H., Im, D., Hur, B., Chung, D. and Kim, K. (1998) Reactions of resistance to brown planthopper (Nilaparvata lugensStal.) in japonica rice cultivars. RDA J. Crop Protc. 40 (1): 10-15.

Nanda, U. K., Dash, D. and Rath, L. K. (1997) Antibiosis in some rice varieties to the brown planthopper, Nilaparvata lugens (Stal). Pest Manag. Econ. Zool., 5 (2): 101-105.

Natio, A. (1964) Methods of detecting feeding marks of leaf and planthopper and its application. Plant Prot. Japan. 18 (12): 482-484.

Paguia, P., Pathak, M. D. and Heinrichs, E. A., (1980) Honeydew excretion measurement techniques for determining differential feeding activity of biotypes of Nilaparvata lugenson rice varieties. J. Environ. Entomol.,73: 35-40.

Painter, R. H., (1951) Insect resistance in crop plants.Macmillian Co., New York, pp. 520.

Panda, N., and Heinrichs, E. A. (1983) Levels of tolerance and antibiosis in rice varieties having moderate resistance to the brown planthopper, Nilaparvata lugens(Stal.) (Hemiptera: Delphacidae). Environmental Entomology, 12(4), 1204-1214.

Pathak, M. D. and Heinrichs, E. A. (1970) Honeydew Excretion Measurement Techniques for Determining Differential Feeding Activity of Biotype of Nilaparvata lugenson Rice Varieties. J. Econ. Entomol. 73:35-40.
Qiu, Y., Guo, J., Jing, S., Zhu, L and He, G. (2010) High-resolution mapping of the brown planthopper resistance gene Bph6 in rice and characterizing its resistance in the 9311 and Nipponbare near isogenic backgrounds.Theoretical and Applied and Genetics.121: 16011611.

Rapusas, H. R., \&Heinrichs, E. A. (1987) Varietal resistance to insect pests in rice. Proc. 11th Internat. Cong. Pl. Prot, 11, 339-344.

Reddy, B. N., Lakshmi, V. J., Maheswari, T. U., Ramulamma, A., and Katti, G. R. (2016) Non preference/Antixenosis mechanism to brown planthopper, Nilaparvata lugens (stal) in selected rice entries. Journal of Research PJTSAU, 44(1/2), 1-10.

Reddy, K. L., Pasalu, I. C. and Reddy, D. D. R. (2005) Studies on antibiosis mechanism of resistance in rice against brown planthopper, Nilaparvata lugens(Stal.). Ind. J. Ent. 67(2): 140143.

Senguttuvan, T., Gopalan, M. and Chelliah, S. (1991) Impact of resistance mechanisms in rice against the brown planthopper, Nilaparvata lugensStal. (Homoptera: Delphacidae). Crop Protc.10 (2): 125128.

Shivamurthappa, (1993) Management of brown plant hopper, Nilaparvathalugens.Ph.D thesis: University of Agricultural sciences, Bangalore.

SiddeGowda and Gubbaiah, (2009) Rice leaf and planthopper scenario in Southern Karnataka Paper presented in Group discussion on leaf and planthoppers held at IIHR, Hesaragatta, Karnataka on 5th December, 2009.

Siddegowda, D. K. (2009) Screening of rice germplasm against brown planthopper, Nilaparvata lugens(Stal.).Annual meeting Entomology, University of 
agricultural sciences, Bangalore, Mandya, Karnataka, India. Pp 170-173.

Soundararajan, R. P., Chitra, N. and Gunathilagaraj, K. (2002) Evaluation of antibiosis resistance to brown planthopper, Nilaparvata lugens (Stal) in rice.J. Appl. Zool. Res., 13 (1): 14-18.

Wang, H., Shi, S., Guo, Q., Nie, L., Du, B., Chen, R.,... \&He, G. (2018) Highresolution mapping of a gene conferring strong antibiosis to brown planthopper and developing resistant near-isogenic lines in 9311 background. Molecular breeding, 38(8), 107.

Way, M. J., \&Heong, K. L. (1994) The role of biodiversity in the dynamics and management of insect pests of tropical irrigated rice - a review. Bulletin of Entomological Research,84(4), 567587.

Wu, J. T., Heinrichs, E. A. and Medrano, F. G. (1986) Resistance of wild ricesOryzaspp. to the brown planthopper, Nilaparvata lugens (Homoptera: Delphacidae). Environ. Entomol., 15: 648-653.

Yang, L., Han, Y., Li, P., Wen, L. andHou, M. (2017) Silicon amendment to rice plants impairs sucking behaviors and population growth in the phloem feeder Nilaparvata lugens (Hemiptera: Delphacidae). Scientific Reports, 7(1), 110.

\section{How to cite this article:}

Bodhnapod Navin Gangaram, Basana Gowda, S. S. Shaw, S. K. Behera, G. Guru Pirasanna Pandi, Prajna Pati, Mayabini Jena, S. Raghu, G. Prashanthi and Naveen Patil. 2019. Evaluation of Rice Genotypes of Sikkim and Tripura for Resistance to Brown Planthopper, Nilaparvata lugens (Stal). Int.J.Curr.Microbiol.App.Sci. 8(08): 2185-2200.

doi: https://doi.org/10.20546/ijcmas.2019.808.254 